\title{
Soil-transmitted helminths, intestinal protozoa and Clonorchis sinensis infections in southeast China
}

Yan Feng ${ }^{1}$, Kegen Yu ${ }^{1}$, Hualiang Chen ${ }^{1}$, Xuan Zhang ${ }^{1}$, Qiaoyi Lu' ${ }^{1}$ Xiaoxiao Wang ${ }^{1}$, Xueying Zhang², Linong Yao ${ }^{1 *+}$ and Wei Ruan ${ }^{1 *+}$ (D)

\begin{abstract}
Background: Extensive parasitic diseases epidemiology in Zhejiang province has not been carried out since the second national survey in 2004. Therefore, dynamics in prevalence and infection pattern of the major intestinal parasites should be explored.

Methods: The distribution of three parasites including soil-transmitted helminths (STH), intestinal protozoa and C. sinensis in Zhejiang from 2014 to 2015 were explored. Kato-Katz technique was used for STH and C. sinensis detection, whereas transparent adhesive paper anal swab was used for pinworm detection, and iodine smear was used for protozoa detection. A questionnaire survey on alimentary habits and sanitary behaviors was conducted in half of the studied counties.

Results: This study recruited 23,552 participants: 19,935 from rural and 3617 from urban area. Overall prevalence of intestinal helminth infections was $1.80 \%$. In this study, seven helminth species were identified including A. duodenale, N. americanus, Trichuris trichiura, Ascaris lumbricoides, C. sinensis, Fasciolopsis buski and pinworm. The average prevalence of STH infection was 1.71\%: 1.94\% in rural and $0.44 \%$ in urban area. Hookworm was the most prevalent infection at 1.58\%: $1.79 \%$ in rural and $0.44 \%$ in urban area. Prevalence varied considerably in the studied counties. Prevalence was highest in Yongkang county at $10.25 \%$. Only $2.79 \%$ of children from rural area were infected with pinworm. A proportion of $0.40 \%$ of rural participants were infected with protozoa, whereas Endolimax nana was the most prevalent at $0.23 \%$. C. sinensis showed infection only in one man. Awareness on C. sinensis was $24.47 \%$ in rural and $45.96 \%$ in urban area, respectively.

Conclusions: Prevalence of STH and protozoa infections declined considerably whereas C. sinensis infections remained few in Zhejiang province compared with the prevalence reported in previous large scale surveys (19.56\% for national STH infection in 2004, 18.66\% and 4.57\% for provincial STH and protozoa infection, respectively in 1999). The findings of this study showed that hookworm, mainly N. americanus remained a parasitic threat to population health, mainly in the central and western Zhejiang. Therefore, more health education regarding fertilization and farming habits is necessary in rural areas. The awareness concerning hookworm infection should be reinforced.
\end{abstract}

\footnotetext{
*Correspondence: Inyao@cdc.zj.cn; wruan@cdc.zj.cn

†Linong Yao and Wei Ruan contributed equally to this work

${ }^{1}$ Department of Infectious Disease Prevention and Control, Zhejiang

Provincial Center for Disease Control and Prevention, Hangzhou 310051,

China

Full list of author information is available at the end of the article
}

(C) The Author(s) 2021. Open Access This article is licensed under a Creative Commons Attribution 4.0 International License, which permits use, sharing, adaptation, distribution and reproduction in any medium or format, as long as you give appropriate credit to the original author(s) and the source, provide a link to the Creative Commons licence, and indicate if changes were made. The images or other third party material in this article are included in the article's Creative Commons licence, unless indicated otherwise in a credit line to the material. If material is not included in the article's Creative Commons licence and your intended use is not permitted by statutory regulation or exceeds the permitted use, you will need to obtain permission directly from the copyright holder. To view a copy of this licence, visit http://creativecommons.org/licenses/by/4.0/. The Creative Commons Public Domain Dedication waiver (http://creativeco mmons.org/publicdomain/zero/1.0/) applies to the data made available in this article, unless otherwise stated in a credit line to the data. 
Keywords: Parasitic intestinal diseases, Soil-transmitted helminths, Protozoa infections, Clonorchis sinensis, Prevalence

\section{Background}

Intestinal nematode infections, also known as soil-transmitted helminths, including ascariasis, hookworm disease, and trichuriasis are a huge burden globally. These infections are associated with an estimated 5.19 million disability-adjusted life year (DALY), ranking first in the list of the estimated DALYs of Neglected Tropical Diseases (NTDs) [1]. Studies report that most cases of highburden NTDs actually occur in Asian countries including China, India, and Indonesia [1]. Helminthiasis, protozoan infection, and clonorchiosis are most frequently reported parasitic diseases in China. However, their prevalence are likely to be underestimated since their symptoms are not clear at an early stage of infection [2-5].

Soil-transmitted helminth (STH) infections are widely distributed in tropical and subtropical areas. In addition, they are linked to poor sanitation. Therefore, STH infections are prevalent in poor countries or regions [6]. Studies reported that $>880$ million children acquire STH yearly [6]. In 2010, a total of 5.3 billion people and 1.0 billion school-aged children living in areas regarded as habitats presented with at least one STH species. Furthermore, $69 \%$ of these patients were living in Asia [7]. In 2003, the prevalence of all STH species including roundworm (Ascaris lumbricoides), whipworm (Trichuris trichiura) and hookworms (Necator americanus and Ancylostoma duodenale) [8] was highest in China, followed by Southeast Asia and India [9]. However, only a few studies have explored prevalence of STH species. Studies conducted in South Asia and South East Asia reported that in 2018, roundworm was the main cause of STH at $18 \%$, followed by whipworm at $14 \%$ and hookworm at $12 \%$ [10]. China carried out two national surveys on parasitic infections in 1992 and 2001-2004. The overall prevalence of roundworm, whipworm and hookworm in 1992 was $47.0 \%, 18.8 \%$, and $17.2 \%$, respectively [11], whereas the prevalence in 2004 was $12.72 \%, 4.63 \%$ and $6.12 \%$, respectively [12]. However, these large-scale STH infection investigation has been scanty in recent years. $\mathrm{STH}$ infection prevalence and distribution pattern is likely to exhibit great dynamics due to current economic development as well as sanitation improvement.

Inadequate clean water, sanitation, and poor hygiene may contribute to transmission of intestinal protozoa including cryptosporidium, Giardia intestinalis and Entamoeba histolytica $[13,14]$. Therefore, intestinal protozoa infections occur predominantly in developing countries.

Cryptosporidium, the causative agent for cryptosporidiosis, is one of the common causes of diarrhea and gastroenteritis in humans. Furthermore, it causes a great health burden to children and immunocompromised persons [15-17]. Incidences of cryptosporidiosis ranges from $1.4 \%$ to $10.4 \%$ in various countries. In addition, the rate is higher in low-income countries (5-10\%) compared with the rate in developed nations (1\%) [18]. G.intestinalis causes giardiasis, which is also a common cause of chronic diarrhea. Cases of giardiasis are mainly reported in developing countries among children. In developing countries, childhood giardiasis prevalence range is $20-30 \%$, whereas only $2-3 \%$ prevalence is reported in the developed countries [17]. Amebiasis Amebiasis caused by E. histolytica affects 50 million people leading to 100,000 annual deaths globally [19]. In China, a national survey carried out in 1992 reported that the infection rates of G. intestinalis was $2.52 \%$ whereas that of E. histolytica was $0.95 \%$ [11]. However, the national survey performed between 2001 and 2004 reported a significant decrease in the prevalence. In Zhejiang province, the prevalence of $G$. intestinalis decreased from $3.85 \%$ to $1.30 \%$ whereas the prevalence of E. histolytica decreased from $1.5 \%$ to $0.14 \%$ compared with the previous survey [20].

Human liver fluke is also a common threat to people's health in East Asia. C. sinensis is the most common human liver fluke parasite, whose infection results in adverse effects. C. sinensis causes severe cholangiocarcinoma, therefore, it was considered a group 1 biological carcinogen by the International Agency of Cancer Research in 2009 [21]. Moreover, due to its high prevalence, $C$. sinensis causes a huge health burden in East Asian countries including China. Approximately 15 million people were infected with $C$. sinensis globally in 2004 [22], and $85 \%$ of these infections were recorded in China [23]. Infection rate of C. sinensis was $0.365 \%$ [24] in 1992 and the rate increased to $0.58 \%$ [12] in the early 2000s. Two epidemic zones of $C$. sinensis were reported in China: Heilongjiang and Liaoning provinces in northern China, and Guangdong and Guangxi provinces in southern China. Zhejiang province is located in southeast China. Prevalence of $C$. sinensis was low in Zhejiang province. In the second national survey, prevalence of C. sinensis in Zhejiang was $0.01 \%$ [20], which was significantly lower compared with the national average (0.58\%) [12]. However, parasite transmission and population composition has greatly changed rapidly in recent decades. Therefore, it is important to perform a survey to explore the distribution of $C$. sinensis in Zhejiang province [25]. 
The epidemiology of infections from the three parasite species introduced above (STH, intestinal protozoa, and $C$. sinensis) have not been recently explored through large-scale studies, as the last two national surveys were completed in 1992 and 2003, respectively. However, over a decade later, a high-speed development period has been observed in China and some parasitic infection rates have declined. However, infections like giardiasis persisted among the children and underprivileged communities show increased rates [18]. This study sought to explore the distribution of three different parasites in Zhejiang province. The findings of this study will contribute to eradication and prevention of intestinal parasitic infections in Zhejiang province thus reducing the health burden associated with these parasites.

\section{Methods}

\section{Study sites and sampling}

Zhejiang province is located in the southeast China. It is characterized by a monsoon season, temperate climate, and a mountainous landscape. Notably, $74.63 \%$ of its landscape is mountainous and hilly [26]. It is among the smallest provinces in China. An extensive field sample collection and survey was carried out in 34 counties out of the 89 counties (38.20\%) in Zhejiang province from 2014 to 2015 as part of the third national parasitic infection survey. Each study county was considered a single study site, and was assigned to rural or (and) urban area. All the study sites were presented in Additional files 1 and 2. Prevalence of STH and C. sinensis was determined in each study site. Presence of intestinal protozoa was explored in the rural areas. Participants were included based on a multi-stage cluster sampling technique. The number of all rural participants recruited in this study was based on the national monitoring data using binomial distribution. The smallest selection unit in rural setting was a village comprising 250 participants. Then, the number of rural sites, proportionate to the county rural population size, was calculated with regard to the precious two numbers. Each county was subdivided into three or four categories based on the town-level GDP (2011 Zhejiang provincial statistic yearbook). One town was randomly selected for per each GDP level. One village was then randomly selected from the town. The number of urban participants was calculated using Poisson distribution with respect to prevalence in previous national study findings of 27 provinces in 2004 [27]. The smallest unit for the urban site was neighborhood comprising 250 participants. The number of all urban sites was determined based on the two previous numbers. The number of urban sites in each county, proportionate to the county's urban population size, was assigned and was equivalent to the number of the studied neighborhoods.
Districts were chosen randomly from each county and then neighborhoods were selected randomly from each district. In each village and neighborhood, two-hundred and fifty subjects were sampled by randomly selecting the families. All family members were requested to participate once a family was selected.

\section{Study population and sample collection}

Permanent residents in the chosen rural sites were underwent diagnosis for $\mathrm{STH}$, C. sinensis and intestinal protozoa infection. In addition, children aged 3-6 years old were examined for pinworm infection. Permanent residents in the urban areas were screened for both STH and C. sinensis infection. Demographic variables, such as sex, age, ethnicity, occupation, and education level of all participants were recorded. Approximately $30 \mathrm{~g}$ stool sample was collected from each participant. An additional anal swab was taken from all child participants.

\section{Ethics approval and consent to participate}

This study was part of an Epidemiology Survey of Important Parasitic Diseases in China. It was approved by the Ethical Review Committee of National Institute of Parasitic Disease, Chinese Center of Disease Control and Prevention. Written or verbal consents were obtained from each participant. Some elderly participates, mainly in the rural areas were illiterate, therefore, to standardize the informed consent form in Zhejiang province, verbal informed consent was obtained from all the participants before sample collection and face-to-face survey. The study staff explained the content to the participants with the help of the local authorities such as the village leaders and women directors. When the villagers agreed to participate in the study, they sent their own samples themselves or those of their children.

\section{Sample examination}

Kato-Katz technique was used to detect STH and direct faecal smears following WHO recommendation. Iodine solution was used for determination of protozoa cysts [28]. Two thick-smear slides were processed using modified Kato-Katz technique under a light microscope at $10 \times$ and $40 \times$ magnification for eggs detection in each stool sample. In addition, one slide was processed using iodine solution under light microscope at 40 magnification for detection of protozoa cysts. The average number of eggs on two Kato-Katz slides was determined when any helminth egg was detected. The findings were reported as positive or negative for the protozoa cysts. Pinworm eggs were examined under light microscope at $10 \times$ using the transparent adhesive paper anal swab technique and reported as positive or negative for pinworm eggs. 


\section{Stool culture}

Stool samples were cultured for detection of hookworms. Approximately $0.5 \mathrm{~g}$ of each stool sample was spread on spindly filter paper. The filter paper was then placed in a cone-shaped tube with cold boiled water at the bottom of the tube. The sample was then incubated for 4 days at $30{ }^{\circ} \mathrm{C}$. During the incubation, water was added when water levels were low to prevent the tube from drying up. The water at the bottom was collected and examined under anatomical lens for $A$. duodenale or $N$. americanus larvae after spontaneous sedimentation. The species name and the number of larvae were recorded. A maximum of 50 samples per county were cultured.

\section{Infection intensity classification}

The intensity of the infection was determined by eggs per gram (EPG), which was calculated through the formula: EPG=average eggs of the two slides from one sample*24. The intensity of parasites were calculated as follows, intensity of hookworm: $0<\mathrm{EPG}<400, \quad$ intensity $=$ light $; \quad 400 \leq \mathrm{EPG} \leq 3000$, intensity $=$ moderate; $\quad E P G>3000, \quad$ intensity $=$ heavy; intensity of $A$. lumbricoides: $0<\mathrm{EPG}<5000$, intensity $=$ light; $5000 \leq \mathrm{EPG} \leq 50000$, intensity $=$ moderate; EPG $>50000$, intensity $=$ heavy; intensity of $T$. trichiura: $0<\mathrm{EPG}<1000$, intensity $=$ light; $1000 \leq \mathrm{EPG} \leq 10000$, intensity $=$ moderate; $E P G>10000$, intensity $=$ heavy .

\section{Quality control}

Two trained laboratory staff examined the two KatoKatz slides for each stool sample. An experienced parasitologist then re-checked the slides in case the two trained staff reported inconsistent findings. Afterwards, an experienced parasitologist re-observed the iodine slide when cysts of protozoa were detected. Lastly, $10 \%$ of the positive samples and $5 \%$ of the negative samples were then examined by the provincial experienced parasitologists.

\section{Questionnaire survey}

Questionnaires (Additional files 3 and 4) were developed for this study whereby surveys were carried out in 17 counties randomly selected from the 34 study counties. A total of 60 subjects including those under stool examination in each study unit were filled the questionnaires based on alimentary habits. Notably, sanitary behaviors were recorded for the rural areas.

\section{Statistical analysis}

Questionnaire data and laboratory examination findings were recorded in independently by two research staffs using Epi-Info 3.5.4 (CDC, GA, USA). Data were then compared to avoid discrepancies, logical errors and missing values. Statistical analysis was conducted performed using SPSS 24 software (SPSS Inc., IL, USA). Pearson's chi-squared test ( $\mathrm{X} 2)$ was used to compare the crude associations between binary and independent variables. Significance level for all the tests was set at $<5 \%(P<0.05)$.

\section{Results}

\section{Characteristics of study sites}

Seventy-eight villages in the rural area and 14 urban neighborhoods were chosen for this study. Landscapes of selected villages (rural study sites) were: mountainous $(28,35.90 \%)$, hilly $(25,32.05 \%)$, plain $(20,25.64 \%)$ and others $(5,6.41 \%)$. On the other hand, the urban study sites were mainly characterized by plain landscape (6, 42.86\%). Most villages $(76,90.48 \%)$ had access to tap water. Most villages did not report the habit of eating raw meat, however, one village in Wenzhou city ate raw freshwater fish and shrimp. Local drinking and eating habits are presented in Table 1.

\section{Characteristics of participants}

The characteristics of the study population were presented in Table 2. A total of 23,552 participants were included in this study. Among them, 19,935 participants were from the rural whereas 3617 participants were from the urban areas. Number of the female

Table 1 Local drinking and food habits in rural area

\begin{tabular}{|c|c|c|}
\hline \multirow[t]{2}{*}{ Habits } & \multicolumn{2}{|c|}{ The NO. (\%) of villages } \\
\hline & $\mathbf{N}$ & $\%$ \\
\hline \multicolumn{3}{|c|}{ Major drinking water source } \\
\hline Tap water & 76 & 90.48 \\
\hline Well water & 3 & 3.57 \\
\hline Pond water & 2 & 2.38 \\
\hline Spring water & 3 & 3.57 \\
\hline \multicolumn{3}{|l|}{ Raw meat diet } \\
\hline Yes & 0 & 0 \\
\hline No & 84 & $100 \%$ \\
\hline \multicolumn{3}{|c|}{ Raw freshwater fish \& shrimp diet } \\
\hline Yes & 1 & 1.19 \\
\hline No & 83 & 98.81 \\
\hline \multicolumn{3}{|c|}{ Raw vegetable diet } \\
\hline Yes & 50 & 59.52 \\
\hline No & 34 & 40.48 \\
\hline \multicolumn{3}{|c|}{ Air-dried meat and fish } \\
\hline Yes & 28 & 33.33 \\
\hline No & 56 & 66.67 \\
\hline
\end{tabular}


Table 2 Characteristics of participants in rural area and urban area

\begin{tabular}{|c|c|c|c|c|c|c|c|c|}
\hline & \multicolumn{2}{|c|}{ Rural area } & \multicolumn{2}{|c|}{ Urban area } & \multirow[t]{2}{*}{$x^{2} / x_{c}^{2}$} & \multirow[t]{2}{*}{$p$} & \multicolumn{2}{|l|}{ Total } \\
\hline & $\mathrm{N}$ & (\%) & $\mathbf{N}$ & $(\%)$ & & & $\mathrm{N}$ & $(\%)$ \\
\hline \multicolumn{9}{|l|}{ Age } \\
\hline $1-17$ & 2008 & 10.07 & 424 & 11.72 & 9.00 & $<0.05$ & 2432 & 10.33 \\
\hline $18-44$ & 3967 & 19.90 & 836 & 23.11 & 19.473 & $<0.05$ & 4803 & 20.39 \\
\hline $45-60$ & 7012 & 35.17 & 1062 & 29.36 & 3.24 & 0.07 & 8074 & 34.28 \\
\hline$>60$ & 6948 & 34.85 & 1295 & 35.80 & 1.21 & 0.27 & 8243 & 35.00 \\
\hline \multicolumn{9}{|l|}{ Sex } \\
\hline Female & 10487 & 52.61 & 1968 & 54.41 & 4.00 & $<0.05$ & 12,455 & 52.88 \\
\hline Male & 9448 & 47.39 & 1649 & 45.59 & & & 11097 & 47.12 \\
\hline \multicolumn{9}{|l|}{ Ethnicity } \\
\hline Ethnic Han & 19619 & 98.41 & 3580 & 98.98 & 6.55 & 0.01 & 23199 & 98.50 \\
\hline Ethnic She & 303 & 1.52 & 36 & 1.00 & 5.94 & 0.02 & 339 & 1.44 \\
\hline Others & 13 & 0.07 & 1 & 0.03 & $0.88^{\mathrm{a}}$ & 0.35 & 14 & 0.06 \\
\hline \multicolumn{9}{|l|}{ Job } \\
\hline Farmer & 13922 & 69.84 & 869 & 24.03 & $2.8 \times 10^{3}$ & $<0.05$ & 14791 & 62.80 \\
\hline Worker & 1346 & 6.75 & 420 & 11.61 & 104.25 & $<0.05$ & 1766 & 7.50 \\
\hline Housewife & 1522 & 7.63 & 339 & 9.37 & 12.70 & $<0.05$ & 1861 & 7.90 \\
\hline Student & 1250 & 6.27 & 320 & 8.85 & 32.67 & $<0.05$ & 1570 & 6.67 \\
\hline Preschoolers & 856 & 4.29 & 147 & 4.06 & 0.40 & 0.53 & 1003 & 4.26 \\
\hline Officer & 342 & 1.72 & 294 & 8.13 & 479.16 & $<0.05$ & 636 & 2.70 \\
\hline Retired & 204 & 1.02 & 825 & 22.81 & $3.5 \times 10^{3}$ & $<0.05$ & 1029 & 4.37 \\
\hline Others & 493 & 2.47 & 403 & 11.14 & 628.66 & $<0.05$ & 896 & 3.80 \\
\hline \multicolumn{9}{|l|}{ Education level } \\
\hline Illiteracy & 4228 & 21.21 & 482 & 13.33 & 118.91 & $<0.05$ & 4710 & 20.00 \\
\hline Primary school & 8555 & 42.91 & 1204 & 33.29 & 116.93 & $<0.05$ & 9759 & 41.44 \\
\hline Middle school & 5218 & 26.18 & 1099 & 30.38 & 27.64 & $<0.05$ & 6317 & 26.82 \\
\hline High school & 1357 & 6.81 & 470 & 12.99 & 163.78 & $<0.05$ & 1827 & 7.76 \\
\hline College and above & 577 & 2.89 & 362 & 10.01 & 404.75 & $<0.05$ & 939 & 3.99 \\
\hline Total & 19935 & 100 & 3617 & 100 & & & 23552 & 100 \\
\hline
\end{tabular}

${ }^{a}$ If theoretical frequency $(T)$ in the table was between 1 and 5 , correction for continuity (Yate's correction) was performed with $X_{c}{ }^{2}$

participants (10487) was significantly higher compared with that of the male participants (9448) in both the rural and urban sites. The average age of the rural and urban participants was 53 and 49, respectively. Ethnic Han accounted for $98.50 \%$ of the study population, whereas Ethnic She, which was a minority cluster in Zhejiang province accounted for $1.44 \%$ of participants. Type of occupations varied among of participants in both rural and urban areas. Although farming was the predominant occupation in both rural and urban areas, farming rate was significantly higher in rural area compared with that of urban areas. Proportions of the participants who had completed primary school and middle school were similar in rural and urban areas. On the other hand, the proportion of participants with high school, college and above education degrees were significantly higher in urban compared with that in rural areas.

\section{Prevalence of helminth infection}

Overall prevalence of intestinal helminth was $1.80 \%$ in Zhejiang province. Seven helminth species were detected including: A. duodenale, $N$. americanus, T. trichiura, A. lumbricoides, C. sinensis, F. buski and pinworm. Prevalence of STH infection in Zhejiang province was $1.71 \%$. STH prevalence was significantly higher in rural areas $(1.94 \%)$ compared with that in urban areas $(0.44 \%)$ $(P<0.05)$ (Table 3). Hookworm was the most prevalent parasite $(1.58 \%)$, followed by $T$. trichiura $(0.08 \%)$ and $A$. lumbricoides $(0.06 \%)$. The prevalence of the hookworm was higher in the rural areas (1.79\%) compared with that the urban areas $(0.44 \%)(P<0.05)$. T. trichiura and $A$. lumbricoides were only detected in samples from rural areas. Most of the participants presenting with parasite infection exhibited only one type of infection. Three participants $(0.01 \%)$ exhibited co-infection with of T. trichiura infection and $A$. lumbricoides. No participant showed 
Table 3 Prevalence of helminth infection

\begin{tabular}{|c|c|c|c|c|c|c|c|c|}
\hline \multirow[t]{3}{*}{ Parasite } & \multicolumn{8}{|c|}{ The NO. and prevalence of infection } \\
\hline & \multicolumn{2}{|c|}{ Rural area } & \multicolumn{2}{|c|}{ Urban area } & \multirow[t]{2}{*}{$x^{2} / x_{c}^{2}$} & \multirow[t]{2}{*}{$p$} & \multicolumn{2}{|c|}{ Total } \\
\hline & $\mathbf{N}$ & $\%$ & $\mathbf{N}$ & $\%$ & & & $\mathbf{N}$ & $\%$ \\
\hline Any intestinal helminth & 406 & 2.04 & 18 & 0.50 & & & 424 & 1.80 \\
\hline $\mathrm{STH}$ & 387 & 1.94 & 16 & 0.44 & 40.90 & $<0.05$ & 403 & 1.71 \\
\hline Hookworm & 357 & 1.79 & 16 & 0.44 & 35.72 & $<0.05$ & 373 & 1.58 \\
\hline T. trichiura & 20 & 0.10 & 0 & 0 & $6.67^{\mathrm{a}}$ & 0.01 & 20 & 0.08 \\
\hline A. lumbricoides & 13 & 0.07 & 0 & 0 & $4.34^{\mathrm{a}}$ & 0.04 & 13 & 0.06 \\
\hline Fertilized egg & 8 & 0.04 & 0 & 0 & $2.67^{\mathrm{a}}$ & 0.10 & 8 & 0.03 \\
\hline Unfertilized egg & 6 & 0.03 & 0 & 0 & / & $0.60^{b}$ & 6 & 0.03 \\
\hline T. trichiura \& A. lumbricoides & 3 & 0.02 & 0 & 0 & / & $1.00^{\mathrm{b}}$ & 3 & 0.01 \\
\hline C. sinensis & 1 & 0.01 & 0 & 0 & / & $1.00^{b}$ & 1 & 0.004 \\
\hline Fasciolopsis buski & 0 & 0 & 2 & 0.06 & / & $0.02^{b}$ & 2 & 0.01 \\
\hline Pinworm (anal swab) & 18 & 2.79 & NA & NA & NA & NA & 18 & 2.79 \\
\hline
\end{tabular}

NA, not available

${ }^{a}$ If theoretical frequency $(T)$ in the table was between 1 and 5, correction for continuity (Yate's correction) was performed with $X_{c}{ }^{2}$

${ }^{\mathrm{b}}$ If $\mathrm{T}$ in the table was less than 1 , exact probability method was used with only Fisher's exact $P$

more than two types of infections. Analysis of hookworm infection showed a higher prevalence in counties located in the central and western Zhejiang compared with other study counties. Yongkang, a county located in central Zhejiang, for instance exhibited the highest hookworm prevalence (10.25\%), followed by Kaihua (6.80\%) and Jiande County (6.57\%). Hookworm infection was not detected in ten counties (29.41\%). Most hookworm infections (70.24\%) including T.trichiura (100\%), and A. lumbricoides (92.31\%) were of light intensity (Table 4). Male $(60.59 \%)$, old (>60) participants and farmers exhibited higher prevalence of hookworm infections (Table 5). Out of 357 hookworm positive stool samples, 330 (92.44\%, $330 / 357)$ samples in rural areas were cultured, and larvae were detected in $73.94 \%(244 / 330)$ of the samples. $N$. americanus was the predominant $(75.00 \%, 183 / 244)$ species in Zhejiang province (Table 6). The average number of hookworm eggs on larvae negative samples' slides was $6.19 \pm 10.77$ (95\% CI 3.88-8.50). Although the maximal number of hookworm eggs was high (60), most samples $(62.79 \%)$ showed less than 3 eggs per slide.
Out of 646 children tested for pinworm in rural areas using transparent adhesive paper anal swab, only $2.79 \%$ children tested positive for pinworm infection. Pinworm infection rate for boys $(9,2.50 \%)$ was not significant different from that of girls $(9,3.18 \%)\left(\chi^{2}=0.29, P=0.59\right)$. Among the children between three to six years old who were tested, 6 year-old children showed the significantly higher infection rate $(3.85 \%, 8 / 208)$, whereas the 5 yearold children had significantly lower infection rate $(0.62 \%$, $1 / 162)(P=0.08)$.

\section{Prevalence of protozoa infection}

Nine protozoa species were detected in the rural areas. Analysis showed that $0.40 \%$ of the rural participants were infected with protozoa. Notably, Endolimax nana was the most prevalent $(0.23 \%)$ species, followed by Entamoeba histolytica (0.05\%) and Entamoeba hartmani (0.04\%) (Table 7). In addition, Entamoeba coli, Entamoeba polecki, Giardia intestinalis, Trichomonas hominis, lodamoeba butschli, Blastocystis hominis were detected, however, their prevalence was low (Table 7). The positive

Table 4 Infection intensity of STH

\begin{tabular}{|c|c|c|c|c|c|c|c|c|c|}
\hline \multirow[t]{2}{*}{ Intensity } & \multicolumn{2}{|c|}{ The NO. of Hookworm } & \multirow[t]{2}{*}{ Total N (\%) } & \multicolumn{2}{|c|}{ The NO. of $A$. lumbricoides } & \multirow[t]{2}{*}{ Total N (\%) } & \multicolumn{2}{|c|}{ The NO. of T. trichiura } & \multirow[t]{2}{*}{ Total N (\%) } \\
\hline & Rural area & Urban area & & Rural area & Urban area & & Rural area & Urban area & \\
\hline Light & 251 & 11 & $262(70.24)$ & 12 & 0 & $12(92.31)$ & 20 & 0 & $20(100)$ \\
\hline Moderate & 88 & 4 & $92(24.66)$ & 1 & 0 & $1(7.69)$ & 0 & 0 & $0(0)$ \\
\hline Heavy & 18 & 1 & $19(5.09)$ & 0 & 0 & $0(0)$ & 0 & 0 & $0(0)$ \\
\hline Total & 357 & 16 & 373 & 13 & 0 & 13 & 20 & 0 & 20 \\
\hline
\end{tabular}


Table 5 Age and job distribution of hookworm positive participants

\begin{tabular}{|c|c|c|c|c|c|}
\hline \multirow[t]{2}{*}{ Characteristics } & \multicolumn{2}{|c|}{$\operatorname{Sex}(n)$} & \multirow[t]{2}{*}{ Total (n) } & \multirow[t]{2}{*}{ NO. of subjects } & \multirow[t]{2}{*}{ Prevalence (\%) } \\
\hline & Male & Female & & & \\
\hline \multicolumn{6}{|l|}{ Age } \\
\hline $1-17$ & 5 & 2 & 7 & 2432 & 0.29 \\
\hline $18-44$ & 4 & 10 & 14 & 4803 & 0.29 \\
\hline $45-60$ & 45 & 34 & 79 & 8074 & 0.98 \\
\hline$>60$ & 172 & 101 & 273 & 8243 & 3.31 \\
\hline \multicolumn{6}{|l|}{ Job } \\
\hline Farmer & 197 & 124 & 321 & 14791 & 2.17 \\
\hline Worker & 18 & 4 & 22 & 1766 & 1.25 \\
\hline Housewife & 0 & 16 & 16 & 1861 & 0.86 \\
\hline Student & 3 & 2 & 5 & 1570 & 0.32 \\
\hline Preschoolers & 2 & 0 & 2 & 1003 & 0.20 \\
\hline Retired & 5 & 0 & 5 & 1029 & 0.49 \\
\hline Others & 1 & 1 & 2 & 1532 & 0.13 \\
\hline Total & 226 & 147 & 373 & 23552 & 1.58 \\
\hline
\end{tabular}

Table 6 Coproculture result of hookworm positive stool sample in rural areas

\begin{tabular}{lc}
\hline Coproculture result & $\begin{array}{c}\text { The NO. (\%)of } \\
\text { fetal sample }\end{array}$ \\
\hline Larvae positive & $244(73.94 \%)$ \\
N. americanus & $183(55.45 \%)$ \\
A. duodenale & $58(17.58 \%)$ \\
A. duodenale and N. americanus & $3(0.91 \%)$ \\
Larvae negative $_{\text {Total }}{ }^{2}$ & $86(26.06 \%)$ \\
\hline
\end{tabular}

${ }^{\text {a }}$ Not each positive stool was cultured in each study county

Table 7 Prevalence of protozoa infection

\begin{tabular}{lcc}
\hline Protozoa & \multicolumn{2}{c}{ The NO. and prevalence } \\
\cline { 2 - 3 } & $\mathbf{N}$ & $\%$ \\
\hline Endolimax nana & 46 & 0.23 \\
Entamoeba histolytica & 9 & 0.05 \\
Entamoeba hartmani & 8 & 0.04 \\
Entamoeba coli & 4 & 0.02 \\
Trichomonas hominis & 4 & 0.02 \\
Entamoeba polecki & 3 & 0.02 \\
Giardia intestinalis & 3 & 0.02 \\
lodamoeba butschli & 1 & 0.01 \\
Blastocystis hominis & 1 & 0.01 \\
Total & 79 & 0.40 \\
\hline
\end{tabular}

cases were three participants from various villages with multiple hookworm and protozoa infections.

\section{Prevalence of $C$. sinensis}

Clonorchis sinensis was detected only in one man living in the rural area. On the other hand, participants from the urban area tested negative for $C$. sinensis infection. Clonorchiosis exhibited very low infection rate in Zhejiang province.

\section{Sanitary behaviors and alimentary habits}

A total of 2485 participants (12.46\% of rural participants) completed the questionnaire survey on the behaviors related to STH infection in rural study sites. Most of the participants $(89.14 \%)$ exhibited good personal hygiene including washing hands before eating or after using the toilet. However, $12.52 \%$ of the people in rural areas consumed water before boiling. In addition, $21.13 \%$ of the participants used human stools as crop fertilizers whereas $22.78 \%$ participants did not wear shoes when farming. These behaviors may increase the risk of STH infection.

A total of 2485 participants from rural and 483 participants from urban areas participated in the survey on alimentary habits. $12.60 \%$ of all the participants completed the survey on knowledge, risky behaviors, and alimentary habits related to $C$. sinensis infection. The number of participants from the rural areas who had knowledge about transmission route of $C$. sinensis and its effects on health was significantly different from the number of urban 
Table 8 Knowledge, infection risky behaviors and alimentary habits related with C. sinensis

\begin{tabular}{|c|c|c|c|c|}
\hline Investigation & Rural area N (\%) & Urban area $\mathrm{N}(\%)$ & $x^{2}$ & $p$ \\
\hline Know of C. sinensis & $608(24.47)$ & $222(45.96)$ & 92.76 & $<0.05$ \\
\hline Know of C. sinensis transmission route & $357(14.37)$ & $123(25.47)$ & 36.75 & $<0.05$ \\
\hline Know of C. sinensis infection damage to the health & $432(17.38)$ & $127(26.29)$ & 21.00 & $<0.05$ \\
\hline Separate raw and cooked cutting board & $832(33.48)$ & $175(36.23)$ & 1.37 & 0.24 \\
\hline Eating raw freshwater fish and shrimp & $348(14.00)$ & $45(9.32)$ & 7.73 & 0.005 \\
\hline $\begin{array}{l}\text { Would like to try raw freshwater fish and shrimp even knowing the } \\
\text { infection risk }\end{array}$ & 182(7.32) & $59(12.22)$ & 12.97 & $<0.05$ \\
\hline Willing to buy anthelmintic if knowing infected by C. sinensis & $2332(93.84)$ & $457(94.62)$ & 0.43 & 0.51 \\
\hline
\end{tabular}

participants (Table 8). The proportion of the participants who used different cutting boards for raw and cooked food was not significantly different between the rural and urban areas. A small proportion of participants $(14.00 \%$ in rural area and $9.32 \%$ in urban area) ate raw freshwater fish and shrimp. Most of the participants took medicine after $C$. sinensis infection (Table 8).

\section{Discussion}

More than a third of the counties in Zhejiang province were included in this study. Counties included in this study had access to clean water, fairly hygienic conditions and had no special eating habits.

Analysis showed that women were more willing to participate in the survey compared with men in both rural and urban areas. The average age of rural participants was higher compared to that of urban areas. This may be because most old people reside the rural areas whereas most young people moved to the urban areas in search of job opportunities. Urban areas included in this study were mainly previous suburban areas which were converted due to increased urbanization. The most common occupation among urban and rural participants was farming. This may explain why low-level education rate was similar among rural and urban participants. However, higher education (high school and above) was more accessible for urban residents. This observation explained the difference in number of participants who had high school and higher education degrees in urban and rural areas.

Prevalence of the intestinal parasitic infections in Zhejiang province decreased dramatically from $22.84 \%$ [20] in the second national survey (2004) to $2.12 \%$ observed in this study. Overall prevalence varied between the provinces in China as follows: $15.5 \%$ in Sichuan province (southwest China) [29], $0.18 \%$ in Jiangsu province (southeast China) [30], and $2.5 \%$ in Heilongjiang province (north China) [31]. The overall prevalence of STH infection was much higher in our study compared with 59.9\% in Malaysia [32], 39\% in India [33], 9.6\% in southern Thailand, and $76.8 \%, 31.7 \%$ and $25.0 \%$ for hookworm, A. lumbricoides and T. trichiura in southern Lao People's Democratic Republic. However, these comparisons have limitations, since the study in Malaysia targeted populations living in a jungle environment whereas the study in India targeted only rural participants. Prevalence of all STH infections was significantly higher in rural areas compared with that in urban areas. Causes of STH infection showed significant changes in Zhejiang since the second national survey [20]. A total of 17 species of parasites were detected in Zhejiang during the second national survey [20] whereas 16 species of parasites ( 7 species of helminth and 9 protozoa) were detected in this study. Although the number of the species recorded in the two surveys were similar, the prevalence for the two study periods exhibited great variations. Prevalence decreased dramatically from $6.84 \%$ to $0.055 \%$ for A. lumbricoides, $3.64 \%$ to $0.085 \%$ for $T$. trichiura, $8.18 \%$ to $1.584 \%$ for hookworm, $24.42 \%$ to $2.79 \%$ for pinworm, $0.14 \%$ to $0.045 \%$ for Entamoeba histolytica, and $1.00 \%$ to $0.015 \%$ for Giardia intestinalis [20]. The major cause of STH infection also changed from multiple helminth species to hookworm. In addition, prevalence of hookworm was higher compared with that of helminth species. Therefore, A. lumbricoides and T. trichiura were not the leading cause of helminth infection in Zhejiang province contrary to findings from second national survey. Pinworm infection was effectively controlled among children. The considerable reduction in prevalence is attributable to the rapid economic development [34], increased access to tap water and sanitary toilets, and improved personal hygiene habits including washing hands. Reports from the provincial statistical yearbook showed that the per capita income increased by $452.4 \%$ for urban residents and $486.7 \%$ for rural residents. Nationwide accessibility to tap water in the rural areas was $80 \%$ in 2017 [35]. In addition, rural tap water supply rate would stabilise above 99\% from 2018 to 2022 in Zhejiang [36]. A meta-analysis study reported that use of piped water correlated with decreased probability of $A$. 
lumbricoides infection and T. trichiura infections. However, there was scanty evidence for correlation of water availability and hookworm infection [37]. In addition to tap water, nationwide accessibility to sanitary toilet showed a rapid increase from $20.9 \%$ in 1996 to $78.43 \%$ in 2015 [38]. In Zhejiang, coverage rate of sanitary toilet reached $94.60 \%$ households by 2011 [39]. However, in some rural areas, villagers, mainly the elderly, were not willing to use modern sanitary toilet and would use fresh stool as fertilizers. Furthermore, barefooted farming increased their risk to hookworm infection. In the rural areas, men were the main labor force in the field. Higher prevalence of hookworm in male, and participants who were farmers can be attributed to these habits and customs. Hookworm parasite caused the highest number of infections among Zhejiang people. Prevalence of hookworm was inversely proportional to the latitude. In South Asia and South East Asia, hookworm (12\%) was the third most prevalent type of STH. Countrywide prevalence of hookworm was highest in Laos $(30 \%, 17-48 \%)$ followed by Vietnam $(29 \%, 14-52 \%)$ and Cambodia $(28 \%, 18-42 \%)$ [10]. A. duodenale and N. americanus were both endemic in Zhejiang province, however, $N$. americanus was the predominant species. In the neighboring Jiangxi province, which is located to the southwest of Zhejiang, $N$. americanus exhibited high prevalence (80.41\%) [40]. In Thailand, $N$. americanus was the main hookworm identified in northeast region, however, A. duodenale has also been reported in this region, whereas only $N$. americanus was reported in the southern region [41]. In the first national survey, a higher prevalence of $N$. americanus was reported in the southern region, whereas $A$. duodenale was predominant in the northern region [11].

The last national protozoan infection survey was carried out in the first national parasitic survey in 19981999 which reported a prevalence of $10.32 \%$ [24]. In the second national parasitic survey in 2004, protozoa were not included in the detection target. Provincial survey in 1999 reported a prevalence of 4.57\% (717/15698) of protozoa infections and a prevalence of $0.99 \%$ of Entamoeba coli which was the predominant protozoan [20]. The prevalence declined sharply to $0.40 \%$ compared with prevalence from previous surveys, whereas the predominant protozoan in this study was Endolimax nana.

Questionnaire survey concerning C. sinensis revealed that although urban participants had more knowledge regarding Clonorchiosis or $C$. sinensis compared with rural participants, the overall awareness rate in urban participants was less than a half the included participants. More than a half of the participants reported that they would like to eat raw freshwater fish and shrimp even though they knew that these were the transmission routes of the parasites. A total of $9.32 \%$ urban participants ate raw freshwater fish and shrimp, and the rate increased to $12.22 \%$ among participants though they knew the risk of $C$. ssinensis infection. However, the situation was opposite among the rural participants.

This study had a few limitations. Firstly, although Kato-Katz technique for STH detection and direct fecal smears with iodine for cysts of protozoa are recommend by WHO in the field, the sensitivity of these two methods was low. Low sensitivity for hookworm detection is attributed rapid degeneration of delicate hookworm eggs with time $[42,43]$. In this study, eggs were examined within $2 \mathrm{~h}$ after slides were properly prepared to avoid rapid degeneration of the hookworm. Two trained laboratory staff analyzed two slides for each sample to improve sensitivity. Secondly, cluster sampling was used in this study, which has more convenient implementation and lowers the cost of the study, however, it results in less representation of samples.

\section{Conclusion}

The findings of this study show that the prevalence of STH and protozoa infections has been decreased over time. In addition, $C$. sinensis infection was not prevalent in Zhejiang. However, hookworm, particularly $N$. americanus was a parasitic threat to population health, especially in some counties in the central and western Zhejiang. Health education should carry out on use of organic fertilizers and farming habits. Moreover, the awareness concerning hookworm infections should be reinforced.

\section{Abbreviations \\ STH: Soil-transmitted helminthiasis; NTDs: Neglected Tropical Diseases; GDP: Per capita net income.}

\section{Supplementary Information}

The online version contains supplementary material available at https://doi. org/10.1186/s12879-021-06879-x.

Additional file 1: Study sites in rural area.

Additional file 2: Study sites in urban area.

Additional file 3: Knowledge and Behavior of Soil-transmitted helminth and Clonorchis sinensis Questionnaire.

Additional file 4: Knowledge and Behavior of Clonorchis sinensis Questionnaire.

\section{Acknowledgements}

The authors would like to thank Yingdan Chen, Changhai Zhou, Huihui Zhu, Menbao Qian, Tingjun Zhu for providing parasite identification training to this survey and all the CDCs of studied counties in Zhejiang province for providing laboratory and facility.

\section{Authors' contributions}

$Y F, K Y, H C, X Z, Q L, X W$ performed the research. YF performed the data analysis and wrote the manuscript. WR and LY performed the on-site organization and 
quality control. XZ modified the grammar and words of the manuscript. All authors read and approved the final manuscript.

\section{Funding}

This research received funding from Chinese Central Government's transferring Payment and Zhejiang Federation of Humanities and Social Sciences (2021N28). The funders had no role in study design, data collection and analysis, decision to publish, or preparation of the manuscript.

\section{Availability of data and materials}

The datasets analyzed during the current study are not publicly available due to data sharing need the approval of affiliations but are available from the corresponding author on reasonable request.

\section{Declarations}

\section{Ethics approval and consent to participate}

The collection of samples used in this study and the questionnaire survey were conducted with the permission of participants or their parents. The research protocol was reviewed and approved by the Ethical Review Committee of National Institute of Parasitic Disease, Chinese Center of Disease Control and Prevention. Verbal informed consent was obtained from all participants before the sample collection and the face-to-face survey.

\section{Consent for publication}

Not applicable.

\section{Competing interests}

The authors declare no conflicts of interest.

\section{Author details}

${ }^{1}$ Department of Infectious Disease Prevention and Control, Zhejiang Provincial Center for Disease Control and Prevention, Hangzhou 310051, China. ${ }^{2}$ Department of Environmental Medicine and Public Health, Icahn School of Medicine at Mount Sinai, NewYork 10029, USA.

Received: 19 October 2020 Accepted: 15 November 2021 Published online: 27 November 2021

\section{References}

1. Hotez PJ, Alvarado M, Basáñez M-G, Bolliger I, Bourne R, Boussinesq M, Brooker SJ, Brown AS, Buckle G, Budke CM, et al. The Global Burden of Disease Study 2010: interpretation and implications for the neglected tropical diseases. PLOS Negl Trop Dis. 2014;8(7):e2865.

2. Sun Q, Liu X, Hao Y, Li Y, Bai X, Wang F, Liu M. A misdiagnosis of clonorchiasis as gallstone, leading to an unnecessary cholecystectomy: a case report. Am J Emerg Med. 2014;32(11):1442 e1443-1445.

3. Song $L G$, Zheng XY, Lin DT, Wang GX, Wu ZD. Parasitology should not be abandoned: data from outpatient parasitological testing in Guangdong, China. Infect Dis Poverty. 2017;6(1):119.

4. Roure S, Valerio L, Soldevila L, Salvador F, Fernandez-Rivas G, Sulleiro E, Manosa M, Sopena N, Mate JL, Clotet B. Approach to amoebic colitis: epidemiological, clinical and diagnostic considerations in a non-endemic context (Barcelona, 2007-2017). PLoS ONE. 2019;14(2):e0212791.

5. Min-Jun H, Lan S, Zeng-Zhu G. Hookworm disease induced upper gastrointestinal bleeding: a case report. Zhongguo Xue Xi Chong Bing Fang Zhi Za Zhi. 2011;23(5):523-8.

6. Intestinal worms Epidemiology-geographical distribution https://www. who.int/intestinal_worms/epidemiology/en/.

7. Pullan RL, Brooker SJ. The global limits and population at risk of soiltransmitted helminth infections in 2010. Parasit Vectors. 2012;5:81.

8. Intestinal worms-What are intestinal worms (soil transmitted helminthiasis)? https://www.who.int/intestinal_worms/disease/en/.

9. Silva NRD, Brooker S, Hotez PJ, Montresor A, Engels D, Savioli L. Soiltransmitted helminth infections: updating the global picture. Trends Parasitol. 2003;19(12):547-51.

10. Silver ZA, Kaliappan SP, Samuel P, Venugopal S, Kang G, Sarkar R, Ajjampur SSR. Geographical distribution of soil transmitted helminths and the effects of community type in South Asia and South East Asia-a systematic review. PLoS Negl Trop Dis. 2018;12(1):e0006153.

11. Lq X, Sh Y, Zx J, JIY, Lq L, Xj Z. CQ Z: Soil-transmitted helminthiases: nationwide survey in China. Bull World Health Organ. 1995;73(4):507-13.

12. Coordinating Office of the National Survey on the Important Human Parasitic Diseases: a national survey on current status of the important parasitic diseases in human population. Zhongguo Ji Sheng Chong Xue Yu Ji Sheng Chong Bing Za Zhi 2005, 23(5 Suppl):332-340.

13. Painter JE, Gargano JW, Collier SA, Yoder JS. Centers for disease C, prevention: giardiasis surveillance - United States, 2011-2012. MMWR Suppl. 2015;64(3):15-25.

14. Speich B, Marti H, Ame SM, Ali SM, Bogoch II, Utzinger J, Albonico M, Keiser J. Prevalence of intestinal protozoa infection among school-aged children on Pemba Island, Tanzania, and effect of single-dose albendazole, nitazoxanide and albendazole-nitazoxanide. Parasit Vectors. 2013;6:3.

15. Checkley W, White AC Jr, Jaganath D, Arrowood MJ, Chalmers RM, Chen XM, Fayer R, Griffiths JK, Guerrant RL, Hedstrom L, et al. A review of the global burden, novel diagnostics, therapeutics, and vaccine targets for cryptosporidium. Lancet Infect Dis. 2015;15(1):85-94.

16. Sangare I, Bamba S, Cisse M, Zida A, Bamogo R, Sirima C, Yameogo BK, Sanou R, Drabo F, Dabire RK, et al. Prevalence of intestinal opportunistic parasites infections in the University hospital of Bobo-Dioulasso, Burkina Faso. Infect Dis Poverty. 2015;4:32.

17. Speich B, Croll D, Furst T, Utzinger J, Keiser J. Effect of sanitation and water treatment on intestinal protozoa infection: a systematic review and metaanalysis. Lancet Infect Dis. 2016;16(1):87-99.

18. Wang JL, Li TT, Huang SY, Cong W, Zhu XQ. Major parasitic diseases of poverty in mainland China: perspectives for better control. Infect Dis Poverty. 2016;5(1):67.

19. Stanley SL. Amoebiasis. Lancet. 2003:361(9362):1025-34

20. Tu XG, Nong YL, Min HX, Liang CH, Yu KG, Gen JM, Ming ZW, Man CY, Dou LB, Qiu LC. Second sampled survey on the distribution of human parasites in Zhejiang Province. Chin J Parasitol Parasitic Dis. 2001;19(3):145.

21. Bouvard V, Baan R, Straif K, Grosse Y, Secretan B, Ghissassi FE, BenbrahimTallaa L, Guha N, Freeman C, Galichet L, et al. A review of human carcinogens-part B: biological agents. Lancet Oncol. 2009;10(4):321-2.

22. Lun ZR, Gasser RB, Lai DH, Li AX, Zhu XQ, Yu XB, Fang YY. Clonorchiasis: a key foodborne zoonosis in China. Lancet Infect Dis. 2005;5(1):31-41.

23. Qian MB, Chen YD, Liang S, Yang GJ, Zhou XN. The global epidemiology of clonorchiasis and its relation with cholangiocarcinoma. Infect Dis Poverty. 2012;1(1):4.

24. Senhai $Y$, Longqi $X$, Zexiao J, Shuhui $X$, Jiajun H, Yuguang Z, Chang J, Jinxiang $L$, Funiu $X$. Report on the first nationwide survey of the distribution of human parasites in China. Chin J Parasitol Parasitic Dis. 1994;12(4):241-7.

25. Toledo R, Esteban JG, Fried B. Current status of food-borne trematode infections. Eur J Clin Microbiol Infect Dis. 2012;31(8):1705-18.

26. General Introduction of Zhejiang Province http://www.zj.gov.cn/col/ col1568516/index.html.

27. Fang YY, Chen YD, Li XM, Wu J, Zhang QM, Ruan CW. Current prevalence of Clonorchis sinensis infection in endemic areas of China. Chin J Parasitol Parasitic Dis. 2008;26(2):99-103.

28. WHO. Bench aids for the diagnosis of intestinal parasites. 2nd ed. Geneva: World Health Organization; 2019.

29. Wen LJ, Chun TH, Hong $X$, Yang L, Bo Z, Song WZ, Lin C, Ji Z, Lan CY, Li L, et al. Investigation on the status of major human parasitic infections in Sichuan Province in 2015. Chin J Parasitol Parasit Dis. 2019:04:411-6.

30. Bi-xian N, Ming-xue S, Xiang-zhen X, Xiao-ting W, Yang D, Xiao-li J. Analysis of human infection with soil-transmitted nematodes in Jiangsu Province from 2006 to 2015. J Pathogen Biol. 2017;12:1197-202.

31. Lei T, Feng XZ, Tao G, Hui YS, Shuang Y. Current status of key parasitic infections of humans in Heilongjiang Province in 2015. Chin J Parasitol Parasit Dis. 2019;04:411-6.

32. Ngui R, Aziz S, Chua KH, Aidil RM, Lee SC, Tan TK, Sani MM, Arine AF, Rohela M, Lim YAL. Patterns and risk factors of soil-transmitted helminthiasis among orang asli subgroups in peninsular Malaysia. Am J Trop Med Hyg. 2015;2:361-70.

33. Kaliappan SP, George S, Francis MR, Kattula D, Sarkar R, Minz S, Mohan VR, George K, Roy S, Ajjampur SS, et al. Prevalence and clustering of soil-transmitted helminth infections in a tribal area in southern India. Trop Med Int Health. 2013:18(12):1452-62. 
34. Statistical Yearbook Data of 2018 http://tjj.zj.gov.cn/col/col1525563/ index.html.

35. Ministry of Water Resources PsRoC. Statistic bulletin on china water activities. In. 2017;2017:9.

36. Notice on the issuance of Zhejiang Province Water Conservancy Modernization Action Plan (Phase I 2018-2022) http://slt.zj.gov.cn/art/2018/1/ 26/art_1229229426_1916198.html.

37. Strunz EC, Addiss DG, Stocks ME, Ogden S, Utzinger J, Freeman MC. Water, sanitation, hygiene, and soil-transmitted helminth infection: a systematic review and meta-analysis. PLoS Med. 2014;11(3):e1001620.

38. Jie ZM, Wei Y, Fen FY. Distribution disparity of sanitary latrines construction in rural China during 2006-2015. J Environ Health. 2018;35(1):61-4.

39. Min CJ, Jian CZ, Ming LX, Feng WX, Zhong CW, Hua RL. A survey on the situation of rural environmental health conditions in Zhejiang province. Modern Prev Med. 2014;41 (8):1380-1.

40. Ying XS, Hong GZ, Zhe C, Qin HC, Ming LW, Sheng JW, Jun ZX. Current status of human hookworm infection in Jiangxi Province in 2014. Zhongguo Xue Xi Chong Bing Fang Zhi Za Zhi. 2018;4:446-8.

41. Phosuk I, Intapan PM, Thanchomnang T, Sanpool O, Janwan P, Laummaunwai P, Aamnart W, Morakote N, Maleewong W. Molecular detection of Ancylostoma duodenale, Ancylostoma ceylanicum, and Necator americanus in humans in northeastern and southern Thailand. Korean J Parasitol. 2013;51(6):747-9.

42. Elghareeb AS, Younis MS, Fakahany AFE, Nagaty IM, Nagib MM. Laboratory diagnosis of Blastocystis spp. in diarrheic patients. Trop Parasitol. 2015;1:36-41.

43. Tarafder MR, Carabin H, Joseph L, Balolong E, Olveda R, McGarvey ST. Estimating the sensitivity and specificity of Kato-Katz stool examination technique for detection of hookworms Ascaris lumbricoides and Trichuris trichiura infections in humans in the absence of a "gold standard." Int J Parasitol. 2010;4:399-404.

\section{Publisher's Note}

Springer Nature remains neutral with regard to jurisdictional claims in published maps and institutional affiliations.

Ready to submit your research? Choose BMC and benefit from:

- fast, convenient online submission

- thorough peer review by experienced researchers in your field

- rapid publication on acceptance

- support for research data, including large and complex data types

- gold Open Access which fosters wider collaboration and increased citations

- maximum visibility for your research: over $100 \mathrm{M}$ website views per year

At $\mathrm{BMC}$, research is always in progress.

Learn more biomedcentral.com/submissions 